\title{
Review on Manifestations of Rural Hollowing
}

\author{
Norhafiza Abdullah, Ainur Zaireen Zainudin, Nurul Hawani Idris
}

\begin{abstract}
Rural hollowing is a recent geographic phenomenon that has received significant attention in China, which experienced rapid urbanization. It is formed due to many houses was kept empty by the owner and a lot of new rural house were built outside the village and retaining the old ones in the inner village. It has led to the wasteful use of land resources and abandoned the houses. The purpose of this paper is to review recent research on the manifestation of rural hollowing phenomenon around the world. In this regard, is revise done based on two objectives: Firstly, to identify each manifestation of rural hollowing and secondly to examine the characteristics of each manifestation. The review made mainly in accordance with point researchers findings particularly on the Phenomenon of Rural Hollowing in China, Iran, Europe, and other developed countries or regions. The review found that the problems of rural hollowing manifest themselves in the following aspect: Land Hollowing, Population Hollowing, Economic Hollowing, Physical Hollowing, Infrastructure and Social Services Hollowing, and Cultural Hollowing. Each of manifestations has its own characteristics in order to categorize each of the manifestations of rural hollowing. The review is particularly useful especially in Malaysia, and need for further research in Malaysia according to the problems of vacant and idle houses in the rural area.
\end{abstract}

Index Terms: Rural Hollowing, Vacant Houses, Abandonment Land, Manifestations, Characteristics.

\section{INTRODUCTION}

In recent years, much literature has focused on developed countries that seem to face the phenomenon of rural hollowing, wherein some have taken measures to solve the said phenomenon. For example, in Germany, the policy of land consolidation has been devised and implemented; whereas in France, the implementation of revival plan has been carried out; introduction of key settlement measures in England; and Japan performed village regrouping [1], [2]. Reference [3], [4] stated that rapid industrialization and urbanization have caused many villages to decline over the years and also confronting resources scarcity [5], thus contributing to the phenomenon of rural hollowing. The process of urbanization and the difference in income levels were the key factors that drove the pattern of rural

population transfer, as well as population structure and land utilization changes [6]. Reference [3] added that easy access to cheap lands around the villages has contributed to rural hollowing, in which the central areas of rural settlements deteriorate as residents abandon their older houses and build new ones at the rural fringe.

Rural hollowing is an outwardly expansion and inwardly desolation spatial pattern, which occurs because many

Revised Manuscript Received on April 19, 2019.

Norhafiza Abdullah, Department of Real Estate, Universiti Teknologi Malaysia, Johor Bahru. Johor, Malaysia.

Ainur Zaireen Zainudin, Department of Real Estate, Universiti Teknologi Malaysia, Johor Bahru. Johor, Malaysia. Teknologi Malaysia, Johor Bahru. Johor, Malaysia.

Nurul Hawani Idris, Department of Geoinformation, Universiti

houses are kept empty after the residents leave and a lot of new rural homesteads are being built while the old ones are abandoned [1]. Rural hollowing is the integration of various features that is rural land, population, economy, and society [6]. The essence of this scenario lies in the holistic degradation of economic and social function [7]. The phenomenon of rural hollowing may cause a number of negative effects, such as wasteful use of rural land resources [5], village landscape and rural residential environment degradation [5], [8], [9], rural economic stagnation [7], [10], village depopulation and rural decline [2], [4], [11], low efficiency of rural residential land use, lateral expansion of rural dwellings at the expense of farmland loss [4], and decrease in the ability of rural inner development. There is no uncertainty over all countries that there have been relocation individuals from the farmland into the urban communities [4].

These problems contribute to the phenomenon of Hollow Villages that seems to happen in many developing countries across the world, a scenario more pronounced in China [2], [12]. The evolution of hollowed villages is linked closely to the migration of the rural population [13] and the spatial variability of employment opportunities [3], [14]. The Hollow Villages Phenomenon occurs due to the significant loss of land resources in the rural area and the decreasing number of residents in that area due to the significant loss of land resources in the rural area and the decreasing number of residents in that area due to urbanization.

As such, this study explored the types of manifestations of rural hollowing in traditional agricultural areas based on categories. This study also offers valuable implications for future by analyzing the characteristics of each manifestation that may contribute to rural hollowing phenomenon. This paper begins by discussing the manifestation of rural hollowing and the categorization of each characteristic of the manifestation. Lastly, this paper concludes the correlations between the manifestations to determine if a rural area may turn hollow.

\section{MANIFESTATION OF RURAL HOLLOWING}

Manifestations are an event, action, or object that clearly shows or embodies something, especially in theory or an abstract idea. In this regard, the manifestations of rural hollowing explain the actions of owners who abandon their houses. Previous studies have reported Land Hollowing, Population Hollowing, Economic Hollowing, Infrastructure and Social Services Hollowing, and Cultural Hollowing as the manifestations of Rural Hollowing.

Published By: 
Table I Manifestations of Rural Hollowing

\begin{tabular}{|c|c|c|c|c|c|c|c|}
\hline \multirow{2}{*}{ Manifestation } & \multicolumn{7}{|c|}{ Author } \\
\cline { 2 - 8 } & {$[2]$} & {$[3]$} & {$[6]$} & {$[10]$} & {$[13]$} & {$[16]$} & {$[21]$} \\
\hline Land Hollowing & & & & & & & \\
\hline Population Hollowing & & & & & & & \\
\hline Economic Hollowing & & & & & & & \\
\hline Physical Hollowing & & & & & & & \\
\hline $\begin{array}{c}\text { Infrastructure \& Social } \\
\text { Services Hollowing }\end{array}$ & & & & & & & \\
\hline Cultural Hollowing & & & & & & & \\
\hline
\end{tabular}

Table I presents the manifestations drawn from past studies by researchers from other countries. Through this discovery, this paper describes all manifestations of rural hollowing.

\section{A. Rural Land Hollowing}

Land Hollowing refers to the change in the use of land which is increasingly lacking in farming practices by the countryside, which are always closely related to human activities. Land Hollowing refers to the process changes of land use spatial pattern within villages that refers to the changes in cultivated land and construction land [1]. The spatial changes of land use are mainly caused by demographic change, and are directly reflected in the abandonment of farmlands and houses [4], [15], [16]. The distribution of rural settlement shows a special layout that new house centering at the edge of the village leads to a large number of idle land or abandoned old houses [6]. Fig. 1 shows the characteristics of Rural Land Hollowing.

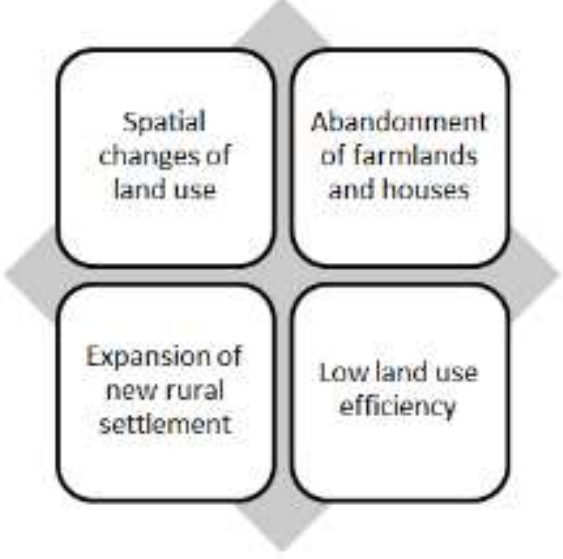

Fig. 1 Characteristics of Rural Land Hollowing (editor from [1], [4], [6], [15], [16])

Fig. 1 demonstrates the connection between one causes to others causes and resulting in the implications from the actions then contribute to the rural land hollowing phenomenon. All these actions called as the characteristic of land hollowing manifestation.

In villages around the city, urban-related industries occupy a large number of agricultural lands in rural areas [7], [17], [18], [19]. In remote villages, land use shifts occur due to demographic changes and directly lead to the neglect of agricultural land and residential homes in rural areas [15]. The movement of population outflow to the city in search of better job opportunities is a major aspect of working in rural areas. Due to limitations of the workforce, some productive agricultural lands are neglected and rural land cannot be used because it is not economically developed. Besides, lack of farmers and their successors to support major agricultural practices is worsening, thus escalating the number of lessdeveloped land.
For the groups migrating from rural to urban, rural employment processes are slow, and there is still a limit to their stay in the city. Most of them face large restrictions when selecting jobs due to their lacking in qualification [8]. Therefore, their jobs are limited to low-income jobs, and their job status is not satisfactory for most of them. This is because; the villagers have no access to social well-being, such as health and education [20]. Most of them begin to realize such shortcomings and decide to migrate to a better area. Reference [10] stated that many have become aware of the drawbacks and they leave their houses vacant in the village in case of returning. For this reason, many uninhabitable residences are either seasonal or permanent.

\section{B. Rural Population Hollowing}

Population hollowing out of rural area is due to population decline, as well as changes in cultural and social structure of these communities due to rapid industrialization [21], [22]. Hollowed villages are communities in which depopulation and housing modernization have led to the abandonment of a significant number of properties, spread throughout the settlement [1], [3] and population loss [16]. Fig. 2 shows the circulation of rural population hollowing process.

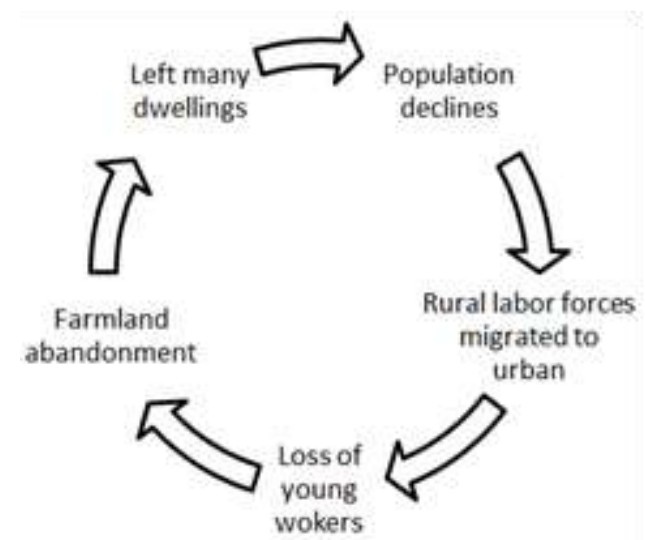

Fig. 2 Characteristics of Rural Population Hollowing (editor from the author [11], [12], [13])

Fig. 2 explain that, a large number of rural labor forces migrate to cities and towns to earn a living [11], [13], [14], [23], [24], and thus leaving many dwellings in the inner village unoccupied [12], [13], [25]. They usually get temporary jobs around or in the city and back in the harvest period [13]. A small part of the seasonal migrants move into the city all year round but return on vacation [13]. Hence, many uninhabited homes are either seasonal or permanent. In addition, with loss of young workers, the structure of the rural population has changed.

Most of farm laborers are gradually replaced by machines, which cause excessive rural labor. Inadequate job opportunities and often with little return are the main reasons for leaving the rural area [14]. Attracted to the quality of life in the city, most young people choose to move to the city [13], [14], [24]. The low social status of farmers has encouraged them to leave their farmworkers and inherit their farmland. The number of rural labor to urban areas is 
increasing. Therefore, the number of residents in the village is decreasing due to urbanization [2], [24].

\section{Rural Economic Hollowing}

From the aspect of economy, in light of urban industrialization, a large number of young people have moved to the city all the year round, except during important festivals when they stay at home. This makes the rural population mostly composed of elderly and children, hence the phenomenon of hollow village [16]. Fig. below illustrated the evolution process of rural economic hollowing that finally resulted in the massive outflow of rural industries.

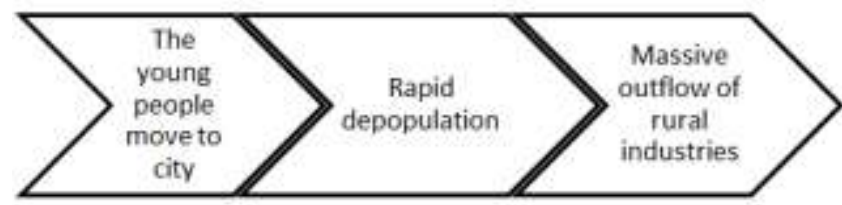

Fig. 3 Evolutions and Characteristics of Rural

Economic Hollowing (editor from the author [3], [16])

Fig. 3 shows that the rapid depopulation has caused massive outflow of rural investment and industries, apart from creating this occurrence of "hollowed village", especially across vast rural areas [3].

\section{Rural Physical Hollowing}

Physical hollowing refers to the neglect and vacancy of rural houses [16], both of which can lead to damage and ultimate abandonment of rural residents [3]. These houses have been left vacant because the occupier or the owner has more than one dwelling or has migrated out of the village (long-term employment in urban areas). After the villagers have moved out of the village, nobody maintains the old houses and they are abandoned. Not selling their homestead leads to serious aging of houses and deterioration in the surrounding environment [12], [16].

Damaged dwellings have different degrees of destruction, ranging from slight to severe, as some vacant houses fall into disrepair; some may even collapse and weeds growing in half meter height. Some get damaged to such a degree that they are deemed unsafe for inhabitation [3]. Fig. 4 shows the characteristics of rural physical hollowing.

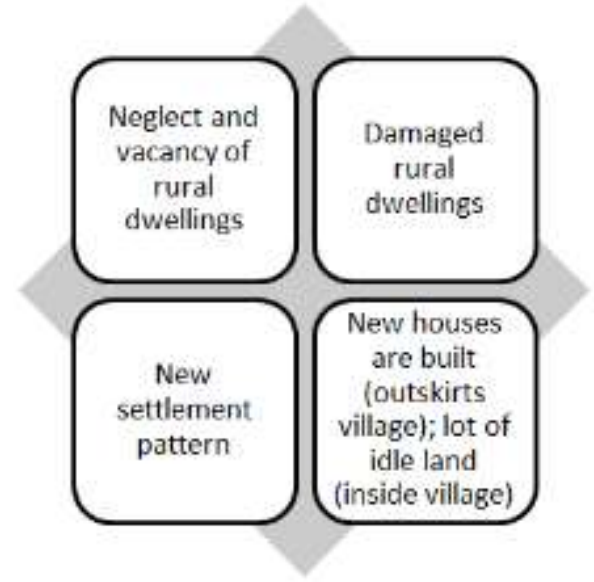

Fig. 4 Characteristics of Physical Hollowing (editor from the author [3], [16])
As a result, nearly all the abandoned dwellings are located in the inner village with spatial concentration and the new settlement pattern occurs as illustrated in fig. 4. The few dwellings located at the fringe of villages are also abandoned. Unlike abandoned dwellings, vacant houses have a more dispersed pattern. [16] stated that new houses are built in the outskirts of the village, but there is a lot of idle land within the village. This is called hollow settlement; households who live in rural settlements of the plains are driven by the desire to gradually move towards the surrounding with new expansion. A new settlement pattern leads a decrease in the freshness of settlement, increment in the rate of non-residential houses, expansion of the ruins area, slump in population density, and sharp contrast with the new expansion [22].

These types of hollow villages depend on varied performances, such as: Centre fall Hollow Village/ overall declined Hollow Village/ Seasonal idle Hollow Village/ Fractured Hollow Village. This review shows that not all the elements (shape, boundary, node, route, and landmark) can be reflected in the hollowing process, as some can only reflect several elements [16]. In order to explore the changes, the following part compares the old and new buildings, roads and nodes, as well as people. These changes may be related to hollowing or may be irrelevant. Hollowing might be a result, or could be a reason for the change [16].

\section{E. Rural Infrastructure and Social Services Hollowing}

Poor infrastructure in rural areas and incomplete urbanization are the main factors that have led to rural hollowing [2]. In the interior of the hollowing, infrastructure construction, as well as the supply of social services, cannot meet the needs of rural communities. The decline in infrastructure and services has accelerated the process of out-of-town movements in the village area, especially amongst the younger ones [23]. The only residents in the countryside are the elderly; resulting in insufficient rural labor for maintenance and construction of new infrastructure [2], [23]. Rural communities continue to decline, thus resulting in a gap between demand and supply of infrastructure and services that ultimately hinder the development of rural communities. From this discovery, the author comes out with fig. 5 to illustrate the character of this infrastructure hollowing.

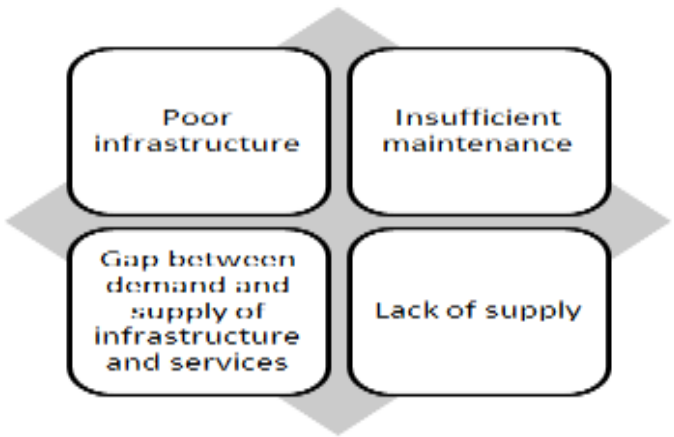

Fig. 5 Characteristics of Infrastructure and Social Services Hollowing (editor from the author [2], [16], [23]) 
In comparison to the advanced infrastructure in urban areas, investment in rural infrastructure seems to be insufficient. Lack of supply is one of the major causes of inadequate construction and maintenance. Rural industries are less competitive and do not offer sufficient results to local governments to meet community demand [2]. In addition, scattered settlements, especially the presence of abandoned houses, can adversely affect the infrastructure facilities in rural communities [16].

\section{F. Rural Cultural Hollowing}

Rural Cultural Hollowing refers to the state of cultural setbacks until cultural practices are no longer practiced by the community. Cultural Hollowing is an impact of urban civilization on rural culture [10]. In short, more modern city cultural practices have influenced cultural practices in rural areas. Working in the city is an important way for farmers to step into modern society and absorb the modern culture [13]. In the meantime, they will make a choice unconsciously, closer to modern civilization and gradually divorce from the original local culture. Traditional rural culture, especially agricultural practices and traditional lifestyle, will be gradually replaced or assimilated [13].

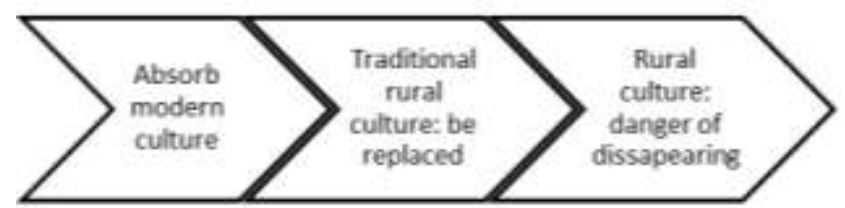

Fig. 6 Evolution and Characteristics of Rural Cultural

Hollowing (editor from the author [3], [10], [13])

The fig. above illustrates the evolution of rural cultural hollowing. The decisions of most communities in the rural area to find a better job in urban may cause many negative effects, especially absorbing the modern culture and adapting to their life. This is more pronounced amidst the young group, who yearn for modern lifestyle [16]. Over time, they become more comfortable with this modern culture and prefer to pursue modern culture, instead of the traditional culture that particularly involves agricultural activities - the main occupation of the rural population. This deteriorates the rural culture. Reference [3] shows that, this situation will lead to cultural practices in rural areas which have been practiced since generations to eventually disappear from the current and future generation practices [2], [3], [10].

\section{RELATIONSHIPS OF ONE MANIFESTATION TO OTHER MANIFESTATIONS}

Based on the discussion presented in Section II pertaining to the manifestations of rural hollowing, it is believed that each manifestation has its own characteristics and most of these characteristics display similarity with other manifestations. In discussing the manifestations of rural hollowing, it actually touches on the story on how the rural area has become hollow, including the causes and the implications. It portrays the change that occurs in the rural area itself. The following figure exhibits the relationships of one manifestation with other manifestations.

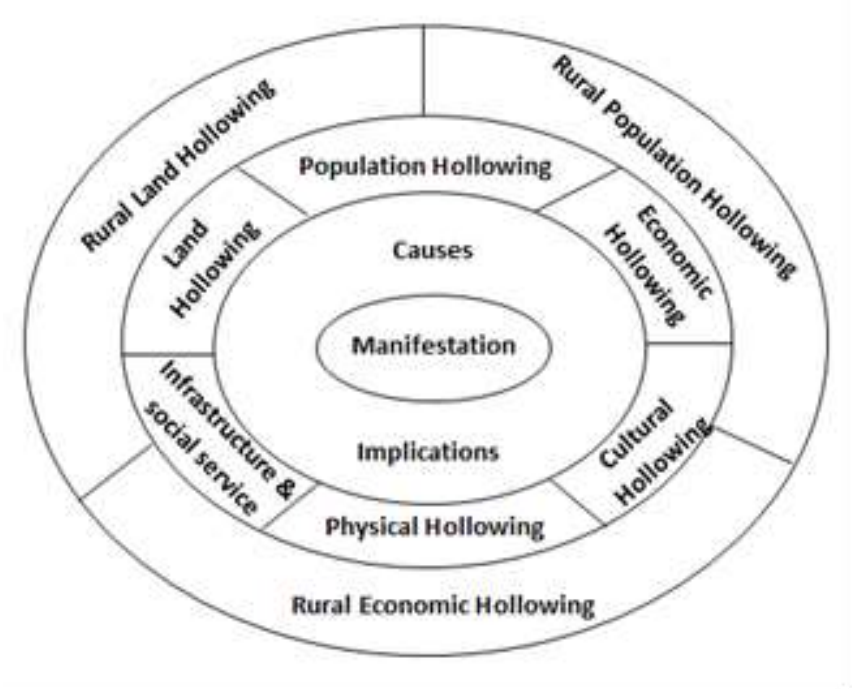

Fig. 7 Relationships of manifestations

Fig. 7 has been developed by the researcher upon the discovery of rural hollowing manifestations. It is believed that the best manifestations in describing this rural hollowing problem are Land Hollowing, Population Hollowing and also Economic Hollowing. Infrastructure and Social Services Hollowing also can be a part of an important point in describing this problem and also can be an effect from those three best manifestations from this discovery.

In a simple explanation, the manifestations of Land, Population and Economic Hollowing appear to be the best manifestations, as seems to be the reason and implication that describe the rural hollowing phenomenon. These manifestations then create other manifestations that can be classified as implications from the rural hollowing problem, such as that noted in Physical Hollowing, Infrastructure and Social Services Hollowing and Cultural Hollowing.

\section{CONCLUSION}

This paper presents the problem of the existing vacant and idle houses in traditional villages. The limitation of this study is that it also focused on the causes and the implications (from manifestation) that occur due to the existence of vacant and idle houses in traditional villages. As a conclusion, the six manifestations discussed in this paper reflect the country that seems to face the rural hollowing issue. Each manifestation has its own characteristics that describe the manifestation itself. Thus, further study is necessary to improve the solutions of rural hollowing and to suggest viable recommendations so that vacant and idle houses can be transformed into beneficial solutions towards meeting the current needs of the population. This is deemed useful to assist related agencies, particularly rural planners and local authorities, to ensure that all needs are adequately met.

\section{ACKNOWLEDGMENT}

This study is a part of ongoing $\mathrm{PhD}$ research is registered with Universiti Teknologi Malaysia (UTM). The authors are gratefully acknowledged and extend our special thanks to 
School of Graduate Studies (SPS), UTM for funding this research through Zamalah Scholarship.

\section{REFERENCES}

1. H. Long, Y. Liu, X. Wu, G. Dong. (April, 2009). Spatiotemporal dynamic patterns of farmland and rural settlements in $\mathrm{Su}-\mathrm{Xi}$-Chang region: Implications for building a new countryside in coastal China. Land Use Policy. 26(2), 322-333. Available: https://www.sciencedirect.com/science/article/abs/pii/S0 264837708000574

2. H. Sun, Y. Liu, K. Xu (June, 2011). Hollow Villages and Rural Restructuring in Major Rural Regions of China: A Case Study of Yucheng City, Shandong Province. Chinese Geographical Science. 21(3), 354-363. Available:

https://link.springer.com/article/10.1007\%2Fs11769-0110474-0

3. Y. Liu, Yu. Liu, Y. Chen, H. Long (2010). The process and driving forces of rural hollowing in China under rapid urbanization. Journal of Geographical Sciences. 20(6), 876-888. Available: https://link.springer.com/article/10.1007\%2Fs11442-0100817-2

4. Y. Liu (May, 2018). Introduction to land use and rural sustainability in China. Land Use Policy. 74, 1-4 Available:

https://www.sciencedirect.com/science/article/abs/pii/S0 264837717315636

5. Y. Liu, Y. Yang, Y. Li, J. Li (April, 2017). Conversion from rural settlements and arable land under rapid urbanization in Beijing during 1985-2010. Journal of Rural Studies. 51, 141-150. Available: https://www.sciencedirect.com/science/article/pii/S07430 16717301304

6. K. Yin, M. Wen, F. Zhang, C. Yuan, Q. Cheng, X. Zhang (October, 2016). Research on the evaluation method of rural hollowing based on RS and GIS technology: a case study of the Ningxia Hui autonomous region in China. Proc. SPIE 10005, 100050P. https://www.spiedigitallibrary.org/conferenceproceedings-of-spie/10005/1/Research-on-theevaluation-method-of-rural-hollowing-basedon/10.1117/12.2241946.full

7. Y. Liu, Zhai (October, 2009). Geographical research and optimizing practice of rural hollowing in China. Acta Geographical Science. 64, 1193-1202.

8. M. Wang (2010). Impact of the Global Economic Crisis on China's Migrant Workers: A Survey of 2,700 in 2009. Eurasian Geography and Economics. Available: https://www.tandfonline.com/doi/abs/10.2747/15397216.51.2.218

9. J. Wang, Y. Liu, Y. Chen (October, 2010). Spatial expansion pattern and its dynamic mechanism of typical rural settlements in Huang-Huai-Hai Plain. Geographical Research. 29(10), 1833-1840.

10. H. Long, Y. Li, Y. Liu, M. Woods, J. Zou (2012). Accelerated restructuring in rural China fueled by 'increasing vs. decreasing balance' land-use policy for dealing with hollowed villages. Land Use Policy. 29, 1122. https://doi.org/10.1016/j.landusepol.2011.04.003

11. Y. Zhang, X. Li, WW. Song, L. Zhai (2016). Land abandonment under rural restructuring in China explained from a cost-benefit perspective. Journal of Rural Studies. 47, 524-532. Available: http://dx.doi.org/10.1016/j.jrurstud.2016.06.019

12. Y. Li, Y. Liu, H. Long, W. Cui (2014). Communitybased rural residential land consolidation and allocation can help to revitalize hollowed villages in traditional agricultural areas of China: Evidence from Dancheng Cpounty, Henan Province. Land Use Policy. 39, 188-198. Available: http://dx.doi.org/10.1016/j.landusepol.2014.02.016

13. Y. Yunjie (2017). From Hollowing Area to Livable Rural Area. Msc. Thesis Landsc. Archit. Wageningen Univ.

14. C. K. Ajaero, P. C. Onokala (2013). The effects of ruralurban migration on rural communities of Southeastern Nigeria. International Journal of Population Research.

15. R. Chen, C. Ye, Y. Cai, X. Xing, Q. Chen (2014). The impact of rural out-migration on land use transition in China: Past, present and trend. Land Use Policy. Available: https://doi.org/10.1016/j.landusepol.2013.10.003

16. S. Li (2014). The renewal of hollow village. Master Sci. Program. Spat. Plan. with an Emphas. Urban Des. China Eur. Blekinge Inst. Technol. (BTH).

17. C. Baiming (1999). The existing state, future change trends in land-use and food production capacities in China. Ambio.

18. Y. Cai (1990). Land use and management in PR China: problems and strategies. Land-use policy.

19. W. Li, T. Feng, J. Hao (2009). The evolving concepts of land administration in China: cultivated land protection perspective. Land Use Policy.

20. J. Shen (2002). A study of the temporary population in Chinese cities. Habitat Int. Available: https://doi.org/10.1016/S0197-3975(02)00013-9

21. D. Thorbeck, A. Isalou, M. Bayat (2014). Rural growth and decay: Analysis of physical-spatial transformation of rural area in Iran. Int. J. Archit. Urban Dev. 44, 25-32.

22. R. Yang, Q. Xu, H. Long (October, 2016). Spatial distribution characteristics and optimized reconstruction analysis of China's rural settlements during the process of rapid urbanization. Journal of Rural Studies. 47, 413424.

Available: https://www.sciencedirect.com/science/article/pii/S07430 16716300833

23. Y. Li, H. Westlund, X. Zheng, Y. Liu (October, 2016) Bottom-up initiatives and revival in the face of rural decline: Case studies from China and Sweden. Journal of Rural Studies. 47, 506-513. Available: https://www.sciencedirect.com/science/article/pii/S07430 16716301267

24. Afroditi Manakou (2018). The phenomenon of rural depopulation in the Swedish landscape. Master's Degree Thesis in Sustainable Urban Planning.

25. Y. Li, Y. Liu, H. Long (2010). Spatio-temporal analysis of population and residential land change in rural China. Journal of Natural Resources. 25(10), 1629-1638.

\section{AUTHORS PROFILE}

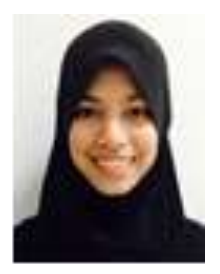

Norhafiza binti Abdullah Education Details:

- $\quad$ Sept 2017 - now (ongoing)

Univesiti Teknologi Malaysia

Field of study: 2nd-year PhD candidate in Land Administration and Development

- $\quad$ Sept 2013 - Jun 2017

Universiti Teknologi Malaysia

Field of study: BSc in Land Administration and Development) (First Class Honour: CGPA 3.71)

May 2012 - May 2013

Negeri Sembilan Matriculation College

Field of study: Module 2 (Math, Chemistry, Physics, Computer Science) 


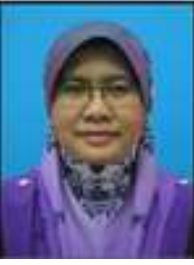

\section{Dr Ainur Zaireen Zainudin}

Education Details:

- $\quad$ Dec 2008 - Mar 2013

Universiti Teknologi Malaysia

Field of study: PhD in Land Administration and Development

National University of Malaysia Jul 2006 - Dec 2007

Field of study: MSocSc in Development Science

- $\quad$ May 1997- Apr 2001

Universiti Teknologi Malaysia

Field of study: BSc in Land Administration and Development

Publications:

- The cooperative-collective sharing arrangement of gated communities in Malaysia

TRIZ Method

Product Design Improvement of Water Dispenser Tap Using

- $\quad$ Sustainable property development by Southeast Asian property companies

- Development of knowledge management strategies for property management companies in Malaysia

- $\quad$ Green property management for commercial buildings

- The typology of gated communities from housing developers' perspective

- The interpretations of gated communities from the Malaysian gating experience

- Local authorities challenges in the implementation of maintenance and operation blueprint

- An audit remark on Malaysian Local Authorities Immovable Asset Management

- Rooftop garden development in Iskandar Malaysia: Growth and Perception

- $\quad$ Sustainability in waterfront development in Malaysia: Barriers to achieving best practices of waterfront development

- Housing developers' initiative in supporting sustainable housing development in Iskandar Malaysia

- Keberkesanan Program Bandar Selamat dari Persepsi Penduduk Kajian Kes: Bandaraya Shah Alam

Projects:

Social Sustainability Achievement in Malaysia Housing Scheme

Achievements:

Best Postgraduate Student UTM 51st Convocation

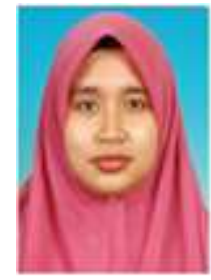

\section{Dr Nurul Hawani Idris}

\section{Education Details:}

PhD - Doctoral Degree in Geography (specialized in Web GIS) from the University of Nottingham United Kingdom (2014)

Thesis: Credibility Assessment and Labelling on Map Mashups

MSc - Master by Research in Geoinfromatics from Universiti Teknologi Malaysia (2007)

Thesis: Performance Testing of Web based Geographic Information System: Case study the use of MapGuide as a map server

BSc - Bachelor Degree in Geoinformatics (Science) (First Class Honour CGPA 3.83). Universiti Teknologi Malaysia (2003)

Thesis: Development of Academic Staff Information System using GIS.

Publications:

- Exploring a linked data approach in accessing physical oceanography archive.

- An integrated augmented reality and crowdsourcing mobile application for tourists.

- Monitoring Outdoor Activity for Elderly Patients Using NearReal Time Fall Detection.

- $\quad$ Assessment of Basic Literacy Skill of Indigenous People.

- $\quad$ Engaging indigenous people as geo-crowdsourcing sensors for ecotourism mapping via mobile data collection: a case study of the Royal Belum State Park.

- Tropical Forest Tree Positioning Accuracy: A Comparison of Low Cost GNSS-enabled devices.

- Indigenous Community Tree Inventory: Assessment of Data Quality

- A Low Cost Mobile Geospatial Solution To Manage Filed Survey Data Collection of Plant Pests and Diseases.
A Conceptual Model of the Automated Credibility Assessment of the Volunteered Geographic Information.

- Evaluating credibility of map mashup through automated metadata assessment.

- $\quad$ Mashups: What looks good must be good?

- Credibility Labelling in Map Mashup Design: Influence on Users' Judgement

- $\quad$ Colour Coded Traffic Light Labelling: An Approach to Assist Users in Judging Data Credibility in Map Mashup Applications.

Professional Memberships:

A Fellow of the Royal Geographical Society (with Institute British Geographers) 2013-2018

A member of the Royal Institute of Surveyors Malaysia 2013-2018

IEEE Geoscience and Remote Sensing Society member 2016-2017. 